\title{
Comments
}

Ecology, 89(3), 2008, pp. 878-879

(C) 2008 by the Ecological Society of America

\section{PREFERENCES FOR DIFFERENT NITROGEN FORMS BY COEXISTING PLANT SPECIES AND SOIL MICROBES: COMMENT}

\author{
Stefanie von Felten, ${ }^{1,2}$ Nina Buchmann, ${ }^{1}$ and \\ Michael Scherer-Lorenzen ${ }^{1}$
}

Harrison et al. (2007) reported on an interesting ${ }^{15} \mathrm{~N}$ labeling study. Under field conditions, they assessed whether coexisting plant species of temperate grasslands show preferences for different chemical forms of nitrogen $(\mathrm{N})$, including ammonium nitrate (inorganic $\mathrm{N})$ and three amino acids of varying complexity (organic $\mathrm{N}$ ). The authors found that all plant species were able to take up the full range of amino acids offered to them, as shown by ${ }^{15} \mathrm{~N}$ and ${ }^{13} \mathrm{C}$ enrichment in plant tissues. However, plants all preferred inorganic over organic $\mathrm{N}$, indicated by higher ${ }^{15} \mathrm{~N}$ enrichments after ammonium nitrate compared to organic $\mathrm{N}$ labeling. We do not object to the general interpretation of the results and the authors' main conclusions. Yet, we would like to comment on the plant uptake of intact amino acids. When testing for significant relationships between excess ${ }^{13} \mathrm{C}$ and ${ }^{15} \mathrm{~N}$ of plants to infer direct uptake of amino acids (Näsholm et al. 1998), Harrison et al. (2007) should have accounted for the different $\mathrm{C}: \mathrm{N}$ ratios of the amino acids used. The amino acid tracers were $\mathrm{U}_{-}{ }^{13} \mathrm{C}_{2}{ }^{-15} \mathrm{~N}$-glycine, $\mathrm{U}_{-}{ }^{13} \mathrm{C}_{3}{ }^{-15} \mathrm{~N}$-serine, and $\mathrm{U}_{-}{ }^{13} \mathrm{C}_{9}{ }^{15} \mathrm{~N}$-phenylalanine (all ${ }^{15} \mathrm{~N} 98 \%$ and ${ }^{13} \mathrm{C} 98 \%$ ), and their ratios of $\mathrm{C}: \mathrm{N}$ atoms are 2:1, 3:1, and 9:1 respectively. While the authors point out that these differences in available $\mathrm{C}$ may affect the preferences of plants and microbes, they omitted to consider the methodological consequences. One common problem (see e.g., Jones et al. 2005) when using dual-labeled amino acids to study organic $\mathrm{N}$ uptake by plants is detecting the ${ }^{13} \mathrm{C}$ label in plants. Due to the high $\mathrm{C}: \mathrm{N}$ ratio of plants and the high abundance of ${ }^{13} \mathrm{C}(\sim 1.08$ atom $\%$ in $\mathrm{C}_{3}$ plants), the dilution of $\mathrm{C}$ is usually $60-150$ times higher than that of ${ }^{15} \mathrm{~N}$ (Näsholm and Persson 2001). Finding a significant relationship between excess

\footnotetext{
Manuscript received 21 June 2007; accepted 27 August 2007. Corresponding Editor: P. M. Groffman.

${ }^{1}$ Institute of Plant Sciences, ETH Zurich, Zurich CH-8092 Switzerland

2 Institute of Environmental Sciences, University of Zurich, Zurich CH-8057 Switzerland.

E-mail: stefanie.vonfelten@ipw.agrl.ethz.ch
}

${ }^{13} \mathrm{C}$ and ${ }^{15} \mathrm{~N}$ requires separating the shift in ${ }^{13} \mathrm{C}$ resulting from direct amino acid uptake from natural variation and analytical error. However, this is often not possible, due to rather low concentrations of tracer ${ }^{13} \mathrm{C}$. As a solution, Näsholm and Persson (2001) suggested to concentrate the labeled fraction of the plant material studied, by extracting the soluble fraction containing the label. For assessing the uptake of intact amino acids using the dual-labeling approach, the critical step is to assure that there is a theoretical possibility of detecting this uptake. From the measured values of $\delta^{15} \mathrm{~N}$ (after labeling with $\left.{ }^{15} \mathrm{~N}\right)$ the theoretical shift in $\delta^{13} \mathrm{C}$ corresponding to $100 \%$ intact uptake can be calculated (Näsholm and Persson 2001). Thereby it can be determined whether this shift is distinguishable from "noise."

Given the high amount of $\mathrm{C}$ in phenylalanine, it is not surprising that Harrison et al. (2007) found a significant relationship between excess ${ }^{13} \mathrm{C}$ and ${ }^{15} \mathrm{~N}$ across all species for this amino acid, but not for glycine and serine. In their paper, Fig. $2 \mathrm{~A}$ shows that shoot ${ }^{15} \mathrm{~N}$ enrichment over all plant species was highest for glycine and lowest for phenylalanine (among organic $\mathrm{N}$ forms), while shoot ${ }^{13} \mathrm{C}$ enrichment was similar for all amino acids (Fig. 2C). This almost opposite pattern for ${ }^{13} \mathrm{C}$ and ${ }^{15} \mathrm{~N}$ enrichment also applies for single species (Fig. 1), roots (Fig. 3), and microbes (Fig. 4). In the latter, ${ }^{13} \mathrm{C}$ enrichment was actually highest when labeled with phenylalanine, and lowest in the case of glycine. We think that these results are due to the different C:N ratios of the three amino acids rather than indicating higher uptake of phenylalanine compared to glycine and serine, which is particularly unlikely given that phenylalanine is the largest and most complex amino acid tested. However, without significant relationships between excess ${ }^{13} \mathrm{C}$ and ${ }^{15} \mathrm{~N}$ in plant tissues, the proportion of amino acids taken up as intact molecule cannot be estimated for glycine and serine. Moreover, although no data on amino acid concentration in the soil solution are shown, it is likely that phenylalanine is the least abundant of the three amino acids, and glycine the most abundant. Thus, the dilution of the added ${ }^{15} \mathrm{~N}$ tracer (equal for all $\mathrm{N}$ forms) by the natural abundance pool was probably least for phenylalanine and strongest for glycine, again leading to an overestimation of phenylalanine uptake when assessed by ${ }^{15} \mathrm{~N}$ labeling.

We fully agree with Harrison et al. (2007), that a rigorous test to detect organic $\mathrm{N}$ uptake by plants requires compound specific isotope analysis (a combination of gas chromatography with isotope ratio mass spectrometry; see e.g., Persson and Näsholm 2001). But clearly, the results of Harrison et al. (2007) demonstrate that the use of the Näsholm et al. (1998) method to infer 
direct uptake of amino acids, without resolving the problem of low ${ }^{13} \mathrm{C}$ enrichment is unreliable, if not misleading.

\section{Acknowledgments}

We thank one anonymous referee for helpful comments on the manuscript.

\section{Literature cited}

Harrison, K. A., R. Bol, and R. D. Bardgett. 2007. Preferences for different nitrogen forms by coexisting plant species and soil microbes. Ecology 88:989-999.

Jones, D. L., J. R. Healey, V. B. Willett, J. F. Farrar, and A. Hodge. 2005. Dissolved organic nitrogen uptake by plants: an important $\mathrm{N}$ uptake pathway? Soil Biology and Biochemistry $37: 413-423$.

Näsholm, T., A. Ekblad, A. Nordin, R. Giesler, M. Högberg, and P. Högberg. 1998. Boreal forest plants take up organic nitrogen. Nature 392:914-916.

Näsholm, T., and J. Persson. 2001. Plant acquisition of organic nitrogen in boreal forests. Physiologia Plantarum 111:419 426.

Persson, J., and T. Näsholm. 2001. A GC-MS method for determination of amino acid uptake by plants. Physiologia Plantarum 113:352-358.

\section{PREFERENCES FOR DIFFERENT NITROGEN FORMS BY COEXISTING PLANT SPECIES AND SOIL MICROBES: REPLY}

\author{
Kathryn A. Harrison, ${ }^{1,3}$ Roland $\mathrm{Bol}^{2}{ }^{2}$ and \\ Richard D. Bardgett ${ }^{1}$
}

The comment of von Felten et al. (2008) raises a number of interesting and valid points concerning the measurement of direct uptake of amino acids by plants. But, as they highlight, none invalidate our main finding that all plant species tested were able to take up the full range of amino acids presented to them, but that all preferred inorganic over organic $\mathrm{N}$ forms (Harrison et al. 2007). Hence, our findings do not support the idea that species-specific partitioning on the basis of chemical

Manuscript received 25 September 2007; accepted 13 November 2007. Corresponding Editor: P. M. Groffman.

${ }^{1}$ Institute of Environmental and Natural Sciences, Soil and Ecosystem Ecology Laboratory, Lancaster University, Lancaster LA1 4YQ United Kingdom.

${ }^{2}$ Cross Institute Programme for Sustainable Soil Function, Institute of Grassland and Environmental Research, North Wyke Research Station, Okehampton, Devon EX20 2SB United Kingdom.

${ }^{3}$ E-mail: k.a.harrison@lancs.ac.uk form provides a mechanism for plants to efficiently partition a limited soil $\mathrm{N}$ pool in temperate grassland.

The first issue raised by von Felten et al. concerns the need to take into account different $\mathrm{C}: \mathrm{N}$ ratios of amino acids when testing for significant relationships between excess ${ }^{13} \mathrm{C}$ and ${ }^{15} \mathrm{~N}$ in plant shoots, which is often used to infer direct uptake of amino acids (e.g., Näsholm et al. 1998, Streeter et al. 2000, Nordin et al 2001, Bardgett et al. 2003, Weigelt et al. 2005). This is an important point that we did take into account in our study, but which requires further clarification. For each $\mathrm{N}$ form, a line was plotted to signify $100 \%$ intact uptake of that amino acid. This line took into account the ratio of C:N within each amino acid, be it 1:2 (glycine), 1:3 (serine), or 1:9 (phenylalanine). The equation of each line was then used to calculate the percentage of direct uptake based on the data we recorded, i.e., how far removed the actual line was from a theoretical maximum of $100 \%$. We found few significant relationships between excess ${ }^{13} \mathrm{C}$ and ${ }^{15} \mathrm{~N}$ in shoot material, and those that were significant only corresponded to between $7-24 \%$ direct uptake. Therefore, we made only cautious conclusions about direct uptake in our study, highlighting that it is likely that a certain proportion of the labeled $\mathrm{N}$ forms were mineralized by microbes to other $\mathrm{N}$ forms prior to plant uptake. Moreover, we fully accept that the use of such relationships to infer direct uptake is problematic in that ${ }^{13} \mathrm{C}:{ }^{15} \mathrm{~N}$ ratios may also be affected by plant endogenous processes, especially when measured in shoot material. As highlighted in our discussion and by von Felten et al., absolute confirmation of direct uptake requires gas chromatography-mass spectrometry (GC-MS) or gas chromatography-combustion-isotope ratio mass spectrometry (GC-C-IRMS) analysis of plant tissue to detect the specific isotopic label of the individual amino acids inside the plant (Bol et al. 2002).

The second point raised by von Felten et al. concerns the apparent opposite patterns of uptake of ${ }^{15} \mathrm{~N}$ and ${ }^{13} \mathrm{C}$ in plant shoots, roots and microbes (Harrison et al. 2007: Figs. 1-4). Looking at the data however, we feel this is not the case for all fractions. For example, in Fig. 1 , while there is greater uptake of ${ }^{15} \mathrm{~N}$ from glycine than phenylalanine for all species tested, there is not a converse pattern of uptake of ${ }^{13} \mathrm{C}$ for each species; for three out of the five species tested there would appear to be no significant difference in uptake of ${ }^{13} \mathrm{C}$ from each of the three $\mathrm{N}$ forms presented. Similarly, looking at Fig. 2c, we found no significant difference in uptake of ${ }^{13} \mathrm{C}$ across all of the $\mathrm{N}$ forms tested; we also found the same to be true for uptake of ${ }^{13} \mathrm{C}$ into plant roots (data not presented). As highlighted by von Felten et al., microbial enrichment by ${ }^{13} \mathrm{C}$ (Fig. 4) did indicate greater uptake of phenylalanine compared to glycine and serine. However, the potential overestimation of phenylalanine uptake into the microbial fraction was noted in our discussion: although we found significantly greater ${ }^{13} \mathrm{C}$ from 
phenylalanine than glycine and serine in the microbial biomass, we highlight that this was most likely due to differences in the number of carbon atoms present in a molecule of each $\mathrm{N}$ form, rather than an indication of preferential use of phenylalanine by microbes. (Glycine and phenylalanine have the same number of $\mathrm{N}$ atoms per molecule, but the number of $\mathrm{C}$ atoms differs dramatically, with glycine having two and phenylalanine having nine. Therefore, a greater amount of ${ }^{13} \mathrm{C}$ from phenylalanine than glycine will be detected per unit uptake of $\mathrm{N}$ by microbes.)

The final point raised by von Felten et al. concerns the potential for differential dilution of ${ }^{15} \mathrm{~N}$ tracer due to variable concentrations of individual amino acids in soil solution. We fully agree with this comment and for this reason we were cautious in drawing conclusions on differential uptake of amino acids, especially since we did not measure concentrations of individual amino acids in soil solution; it is notoriously difficult to obtain realistic measures of soil solution amino acid concentrations because the turnover of amino acids is so rapid (Boddy et al. 2007). We were careful to highlight this issue in our discussion, i.e., that soil concentrations of phenylalanine and serine are likely low relative to other amino acids tested, especially glycine, and hence the uptake of phenylalanine and serine might have been overestimated relative to its importance. While we did not take this dilution effect into account in our study, we believe that it doesn't invalidate our main finding that plants preferred glycine over phenylalanine because shoot ${ }^{15} \mathrm{~N}$ concentration was significantly lower for phenylalanine than for all other $\mathrm{N}$ forms tested. If anything, the likely overestimation of phenylalanine uptake in our study serves to strengthen our conclusion that this amino acid is less preferred by plants than are the simpler $\mathrm{N}$ forms, such as glycine.

In sum, we argue that the points raised by von Felten et al. do not alter our main conclusions, which concern preferential use of, and competition for, different chemical forms of $\mathrm{N}$ by plants and microbes. Also, while they do raise valid points concerning the need for caution in using dual labeled $\left({ }^{15} \mathrm{~N},{ }^{13} \mathrm{C}\right)$ stable isotopes for detecting and quantifying direct uptake of amino acids by plants, as has as been called for by other authors (e.g., Jones et al. 2005), we do not believe our findings are misleading; rather, we draw cautious conclusions from our data which take into account the uncertainty about direct uptake that they raise. One key issue that the comment that Felten et al. does raise, however, is the need to develop suitable analytical techniques which enable improved measurement of the pool size and flux of different amino acids in soil, thereby providing more realistic measures of the availability of these $\mathrm{N}$ forms to plants, and assessment of the direct uptake of different $\mathrm{N}$ forms by plants.

\section{Literature cited}

Bardgett, R. D., T. Streeter, and R. Bol. 2003. Soil microbes compete effectively with plants for organic-nitrogen inputs to temperate grasslands. Ecology 84:1277-1287.

Boddy, E., P. W. Hill, J. Farrer, and D. L. Jones. 2007. Fast turnover of low molecular weight components of the dissolved organic carbon pool of temperate grassland field soils. Soil Biology and Biochemistry 39:827-835.

Bol, R., N. J. Ostle, and K. J. Petzke. 2002. Compound specific plant amino acid $\delta^{15} \mathrm{~N}$ values differ with functional plant strategies in temperate grassland. Journal of Plant Nutrition and Soil Science 165:661-667.

Harrison, K. A., R. Bol, and R. D. Bardgett. 2007. Preferences for different nitrogen forms by coexisting plant species and soil microbes. Ecology 88:989-999.

Jones, D. L., J. R. Healey, V. B. Willett, J. F. Farrar, and A. Hodge. 2005. Dissolved organic nitrogen uptake by plants: an important $\mathrm{N}$ uptake pathway? Soil Biology and Biochemistry $37: 413-423$.

Näsholm, T., A. Ekblad, A. Nordin, R. Giesler, M. Högberg, and P. Högberg. 1998. Boreal forest plants take up organic nitrogen. Nature 392:914-916.

Nordin, A., P. Högberg, and T. Näsholm. 2001. Soil nitrogen form and plant nitrogen uptake along a boreal forest productivity gradient. Oecologia 129:125-132.

Streeter, T. C., R. Bol, and R. D. Bardgett. 2000. Amino acids as a nitrogen source in temperate upland grasslands: the use of dual labelled $\left({ }^{13} \mathrm{C},{ }^{15} \mathrm{~N}\right)$ glycine to test for direct uptake by dominant grasses. Rapid Communications in Mass Spectrometry 14:1351-1355.

von Felten, S., N. Buchmann, and M. Scherer-Lorenzen. 2008. Preferences for different nitrogen forms by coexisting plant species and soil microbes: comment. Ecology 89:878-879.

Weigelt, A., R. Bol, and R. D. Bardgett. 2005. Preferential uptake of soil nitrogen forms by grassland plant species. Oecologia 142:627-635. 